\title{
Article
}

\section{Short-interval observational data to inform clinical trial design in early Huntington's Disease}

Nicola Z. Hobbs $\mathrm{PhD}^{1}$, Ruth E. Farmer $\mathrm{MSc}^{2}$, Elin M. Rees $\mathrm{MSc}^{1}$, James H. Cole $\mathrm{PhD}^{1}$, Salman Haider $\mathrm{MD}^{1}$, lan B Malone $\mathrm{PhD}^{3}$, Reiner Sprengelmeyer $\mathrm{PhD}^{4}$, Hans Johnson $\mathrm{PhD}^{5}$, Hans-Peter Mueller PhD ${ }^{4}$, Sigurd D. Sussmuth MD ${ }^{4}$, Raymund A.C. Roos MD ${ }^{6}$, Alexandra Durr $\mathrm{PhD}^{7}$, Chris Frost $\mathrm{MA}^{2}$, Rachael I. Scahill PhD ${ }^{1}$,

Bernhard Landwehrmeyer $\mathrm{MD}^{4}$, Sarah J Tabrizi PhD ${ }^{1}$ and the PADDINGTON Investigators

\section{Affiliations}

(1) Department of Neurodegenerative Disease, UCL Institute of Neurology, University College London, Queen Square, London, WC1N 3BG, UK

(2) Department of Medical Statistics, London School of Hygiene and Tropical Medicine, London, UK

(3) Dementia Research Centre, UCL Institute of Neurology, University College London, Queen Square, London, WC1N 3BG, UK

(4) Department of Neurology, UIm University, Ulm, Germany

(5) Department of Psychiatry, University of lowa, lowa City, lowa, USA

(6) Department of Neurology, Leiden University Medical Centre, Leiden, Netherlands

(7) ICM (Brain and Spine Institute), APHP- Department of Genetics and INSERM UMR S679, Salpêtrière University Hospital, Paris, France

\section{Corresponding author contact information:}

Prof. Sarah Tabrizi: s.tabrizi@prion.ucl.ac.uk

Address: Box 104, Queen Square, London, WC1N 3BG, UK.

Tel: 0044203448 4053. Fax: 00442076110129.

\section{Other authors' e-mail addresses:}

Nicola Z. Hobbs: nicola.hobbs@ixico.com; Ruth E. Farmer: ruth.farmer@lshtm.ac.uk; Elin M. Rees: elin.rees@ucl.ac.uk; James H. Cole: james.cole@imperial.ac.uk; Salman Haider: s.haider@ucl.ac.uk; Ian B Malone: i.malone@ucl.ac.uk; Reiner Sprengelmeyer: rhs3@st-andrews.ac.uk; Hans Johnson: hans-johnson@uiowa.edu; Hans-Peter Mueller: hans-peter.mueller@uni-ulm.de; Sigurd D. Sussmuth: sigurd.suessmuth@uni-ulm.de; Raymund A.C. Roos: R.A.C.Roos@lumc.nl; Alexandra Durr: alexandra.durr@upmc.fr; Chris Frost: Chris.Frost@Ishtm.ac.uk; Rachael I. Scahill: r.scahill@ucl.ac.uk; Bernhard Landwehrmeyer: bernhard.landwehrmeyer@uni-ulm.de 
Characters in title $=95 / 96$; words in abstract $=250 / 250$; words in Introduction $=$ 248/250; words in main text $=3235 / 3000$; references $=25 / 40$; Tables $=2$; Figures $=2$; Supplemental data $=$ Methods, Results (4 Tables, 1 Figure), Strobe Checklist.

Search Terms $(\max 5):[120] \mathrm{MRI},[164]$ Huntington's Disease, [21] Clinical trials Methodology/study design, [23] Clinical trials Observational study (Cohort, Case control).

Funding sources for the study: This work has been supported by the European Union PADDINGTON project, contract no. HEALTH-F2-2010-261358. RIS is supported by the $\mathrm{CHDI} /$ High Q Foundation, a not for profit organization dedicated to finding treatments for Huntington's disease. This work was undertaken at UCLH/UCL which received a proportion of funding from the Department of Health's NIHR Biomedical Research Centres funding scheme. SJT acknowledges support of the National Institute for Health Research through the Dementias and Neurodegenerative Research Network, DeNDRoN.

Role of the sponsor: The funding organisation were not involved in the design and conduct of the study; collection, management, analysis, or interpretation of the data; preparation, review, or approval of the manuscript; or decision to submit the manuscript for publication.

Financial disclosure/conflict of interest concerning the research related to the manuscript: None

Information on author access to data: SJT had full access to all the data in the study and takes responsibility for the integrity of the data and the accuracy of the data analysis. 


\section{INTRODUCTION [249/250]}

Major efforts are being invested in the development of disease-modifying therapies for neurodegenerative disorders such as Huntington's disease (HD). ${ }^{1}$ Testing their efficacy in clinical trials is a long and expensive process, with low success rates compared with other branches of medicine. ${ }^{2}$ In HD, no phase III studies of putative disease-modifying treatments have been successful, despite many showing promise during early testing.

A wealth of observational data suggests that biomarkers of disease progression may facilitate the evaluation of disease-modifying therapies. ${ }^{3-6} \mathrm{MRI}$-derived neuroimaging measures appear particularly powerful, with data suggesting that substantially fewer patients would be required to detect a reduction in rate of change in MRI biomarkers, compared with clinical measures. ${ }^{3-9}$ However, many biomarkers have only been evaluated over intervals $\geq 12$ months.

It may be advantageous for clinical trials to have efficacy readouts over short intervals such as six months, especially during the early phases, in order to provide confidenceinstilling data that the trial should progress to a larger scale. However, the use of shortinterval biomarkers in clinical trials is critically dependent on their validation in longitudinal observational studies over the same time frame.

Our objectives were to evaluate candidate outcomes for HD trials over 6-, 9- and 15month intervals, across neuroimaging, clinical and cognitive domains. Based on our findings, we present guidelines on the selection of outcomes for rapid readouts in clinical trials. It is hoped these data will directly inform the design of HD trials, facilitating the evaluation of treatments designed to slow the course of this devastating disease. 


\section{METHODS}

\section{Study Design}

This was a longitudinal, case-control observational study in early-stage HD. Assessments were performed at baseline, six and 15 months. The study was approved by the local ethical committees.

\section{Participants}

Between March and October 2011 forty controls and 61 HD patients were enrolled into Work Package 2 of the PADDINGTON study ${ }^{11}$ at Leiden (Netherlands), London (UK), Paris (France) and Ulm (Germany). Patients were recruited from research centres. Controls were spouses, partners or gene-negative siblings in order to match patients to controls as closely as possible in terms of age, education level, background and home life. Patients were required to be stage I of the disease, ${ }^{10}$ defined by a Unified Huntington's Disease Rating Scale (UHDRS) ${ }^{12}$ Total Functional Capacity (TFC) $\geq 11$, indicating good capacity in functional realms. Inclusion criteria included participants being 18-65 years of age, free from major psychiatric and concomitant neurological disorders, not currently participating in a clinical trial and able to tolerate and safely undergo MRI. Written informed consent was obtained from each subject.

\section{Procedures}

Clinical features were assessed using the UHDRS version 99. This included the Total Motor Score (TMS) which measures a range of motor features characteristically impaired in HD including gait, tongue protrusion, ocular function and postural stability; and the TFC scale which measures five components of daily living, including the capacity to work, manage finances and carry out domestic chores. The clinical examination was performed by raters certified by the European Huntington's Disease Network (EHDN) UHDRS-TMS online certification (www.euro-hd.net).

Cognitive features were assessed using the core EHDN cognitive battery, which consists of standard pencil and paper clinical neuropsychological tasks. All raters were trained on the battery and all tests were scripted. Each task is described in the Supplemental Methods.

\section{MRI acquisition}

3T MRI (T1-, T2- and diffusion-weighted) were acquired based on protocols standardised for multi-site use. ${ }^{6,11,13}$ Scan acquisition protocols have been described previously. ${ }^{11}$ Quality control was performed on all datasets in pseudo-real time and rescans were requested where necessary. Data were pseudoanonymised and archived on a secure webportal. To avoid potential bias all image analysis was performed blinded to groupings. 


\section{MRI: macrostructural (volumetric) analysis}

Pre-defined regions-of-interest (ROIs) for the volumetric analysis included the caudate, putamen, white-matter, grey-matter, whole-brain, lateral ventricles and corpus callosum. Cortical thinning was also examined over each lobe (parietal, occipital, temporal and frontal).

The software package MIDAS ${ }^{14}$ was used to delineate the whole-brain, caudate, corpus callosum and ventricles at baseline. ${ }^{11}$ Change in whole-brain, caudate and ventricular volume over the scanning interval was estimated using the Boundary Shift Integral (BSI) technique, ${ }^{15}$ optimised for multi-site data, ${ }^{16}$ within MIDAS software. The BSI is a semiautomated tool which measures volume change over time (atrophy) directly from within-subject registered scan pairs. Change in corpus callosum and putamen volume was estimated by delineating the structures at both time-points, either manually ${ }^{11}$ (corpus callosum) or with BRAINS3 software ${ }^{6,17}$ (putamen) and subtracting the volumes at each time-point. Grey-matter and white-matter volume changes were computed using a fluid-registration approach. . $^{18,19}$

Cortical thickness measures were computed using FreeSurfer software (http://surfer.nmr.mgh.harvard.edu/; version 5.3.0). All scans were run through the longitudinal pipeline ${ }^{20}$ and thickness estimates $(\mathrm{mm})$ were extracted from each region defined by the Desikan-Killiany Atlas and averaged within lobes. ${ }^{21}$

Full details of all volumetric image analysis are provided in the Supplemental Methods.

\section{MRI: microstructural (diffusion) analysis}

Diffusion metrics of fractional anisotropy (FA), mean diffusivity (MD), axial diffusivity (AD) and radial diffusivity (RD) were generated over pre-defined ROls (white matter, corpus callosum, caudate and putamen) for all three visits using a longitudinal registration pipeline. In brief, a common ROI mask was defined in a temporally unbiased 'mid-space' based on within-subject registration of T1 images, before being non-linearly registered to each individual's native FA images for each visit. The mean values were then calculated across all included voxels for the four DTI metrics. This analysis is described in detail in the Supplemental Methods.

All segmentations and registrations were visually inspected for accuracy by trained analysts, blinded to diagnosis. Excluded data-points are described in Supplemental Endpoint Quality Control data.

\section{Statistical analysis}

Statistical analysis was performed by an independent team according to a predefined analysis plan. The repeated measures of each outcome variable were analysed using generalised least squares regression models, with variances of the outcome (and correlations between pairs of measures) allowed to differ both by group and by visit The models included a group factor (early HD or Control), calendar time from baseline (in days) and a quadratic term to allow non-linear change over the three visits to be modelled. The use of 
GLS models that jointly model all available outcomes provides some additional protection against the impact of missing values. Data only requires a "missing at random" assumption rather than the more restrictive "missing completely at random" assumption to give unbiased estimates. (REF) Where outcomes directly measured changes (such as whole-brain atrophy between two visits) the outcome variables in the statistical models were change between baseline and six months (i.e. 6-month interval), change between baseline and 15 months (i.e. 15-month interval) and change between six and 15 months (i.e. 9-month interval). Otherwise outcomes were measures made at baseline, six and 15 months. Linear and quadratic effects of time were included in all models with estimated between-group differences for the 6-, 9- and 15-month intervals calculated using appropriate linear combinations of model parameters. All analyses adjusted forbaseline age, gender and study site as well as interactions with the linear and quadratic effects of time. This was due to an a priori belief that age, gender and study site might affect slopes (and rates of change in slopes) as well as absolute levels of the outcomes. Models for non-imaging outcomes adjusted additionally for educational level (an ordered categorical variable treated as a continuous covariate) and its interactions with linear and quadratic effects of time because education level may affect performance on such outcomes, and education levels were expected to differ systematically between HD and controls.

Longitudinal Effect Sizes (ES) with 95\% confidence intervals (Cls) for the difference in change over each interval were calculated as the covariate-adjusted difference in the mean of the change between HD participants and controls, divided by the estimated residual standard deviation (SD) of change in HD participants. Expression of results as (unit-free) ES permits comparison of changes measured using different metrics. Such ES (when squared) are inversely related to sample-size requirements for clinical trials under the reasonable assumption that a $100 \%$ effective treatment will reduce the mean rate of change in HD cases to that in healthy controls without affecting the variability in these rates. ${ }^{10} 95 \% \mathrm{Cls}$ for the ES were calculated using bias corrected and accelerated (BCa) bootstrapping, with 2000 replications. ${ }^{22}$ Here an ES of two implies that the mean change in HD is two SD away from that in controls. No adjustment for multiple comparisons was made since there is independent scientific interest in each of the variables. $^{23}$ Throughout, a cut-off of $p=0.05$ was used to establish formal statistical significance, with the actual $p$-values also considered in the interpretation of results. All analysis was performed in STATA v12. 


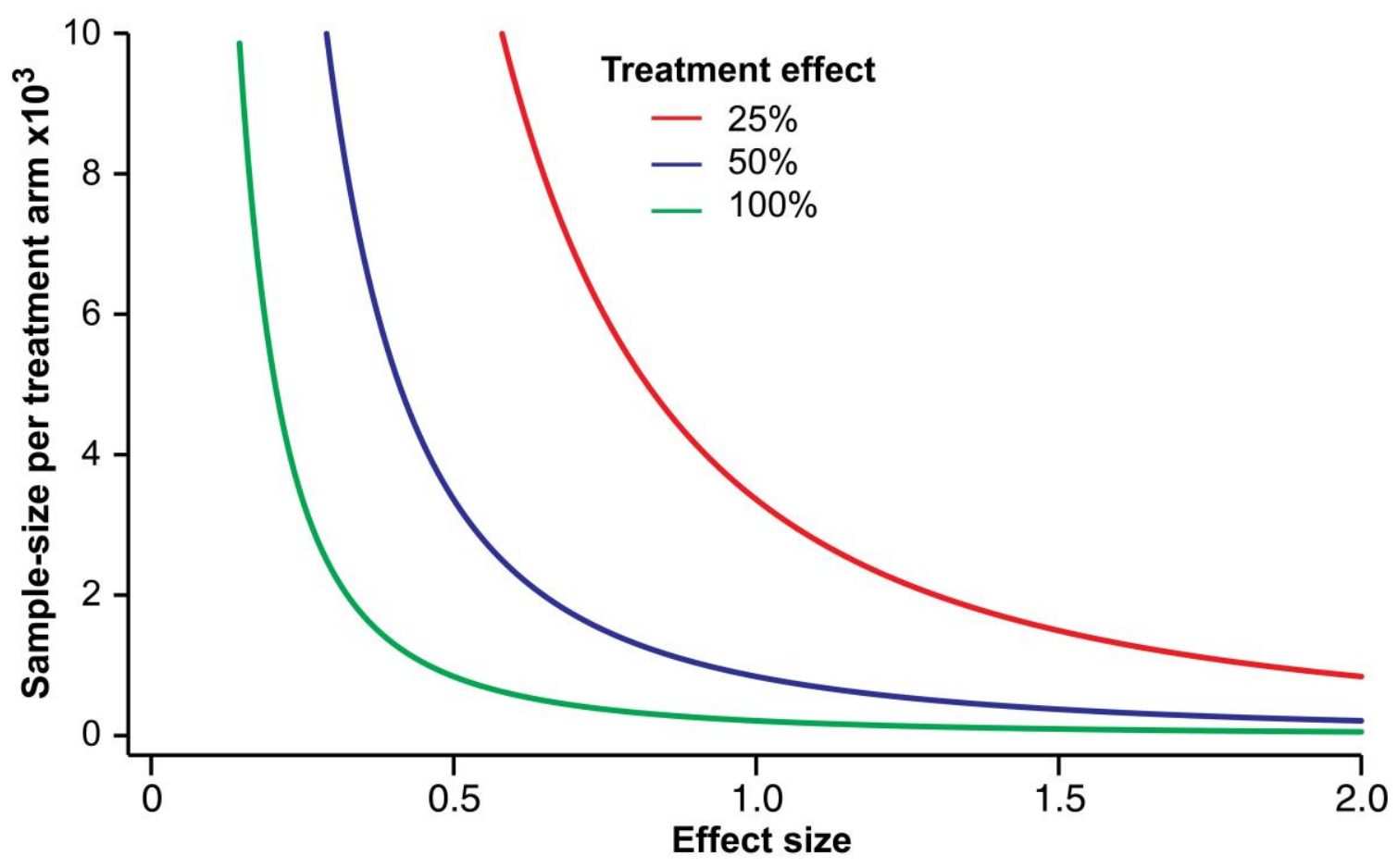

Figure 1 Relationship between effect sizes and sample-size requirements for randomised controlled trials where the outcome is a change measure between two time points. Plots of this relationship are shown for treatments with efficacy levels of $25 \%$ (red), $50 \%$ (blue) and $100 \%$ (green), assuming $90 \%$ power and a 5\% significance level. 


\section{RESULTS}

\section{Participants}

At baseline, five HD participants were granted waivers for being outside disease-stage 1; four were stage 2 , one was stage $3 .{ }^{11}$ All controls and 59/61 HD participants returned for the 6-month assessment; HD drop-out was due to illness $(n=2)$, both returned for the 15-month visit. 37/40 controls and 56/61 HD participants returned for the 15-month assessment; HD drop-out was due to disease-related burden $(n=1)$, inability to tolerate scanning $(n=1)$, treatment for cancer $(n=1)$ and psychiatric burden resulting in the site investigator withdrawing the participant $(n=2)$. Drop out in the control group was due to being the spouse of a withdrawn HD participant $(n=1)$ or personal issues unrelated to the study $(n=2)$.

Age and gender were well-balanced between groups (Table 1). Within the HD group, CAG, disease burden ${ }^{21}$ and TFC were well-balanced between sites (Supplemental Table 1). The average intervals (in months) between assessments in the HD group were 5.76 (1.36)) 9.12 (0.99) and 14.88 (1.33). In the control group the intervals were 5.48 (1.08), $9.08(0.88)$ and $14.50(1.09)$ 
Table 1. Participant demographics at baseline All study participants attended for at least 1 follow up clinical visit.

\begin{tabular}{|c|c|c|c|c|}
\hline \multirow{2}{*}{$\begin{array}{l}\text { Characteristic } \\
\text { Age (Years) }\end{array}$} & \multicolumn{2}{|c|}{ Controls $(\mathrm{N}=40)$} & \multicolumn{2}{|c|}{ HD Stage I $(\mathrm{N}=61)$} \\
\hline & \multirow{2}{*}{$51.42(8.40)$} & \multirow{2}{*}{$\begin{array}{l}28.98- \\
66.64\end{array}-$} & \multirow{2}{*}{$\begin{array}{l}48.65 \\
(10.84) \\
\end{array}$} & \multirow{2}{*}{$\begin{array}{l}23.49 \\
67.29 \\
\end{array}$} \\
\hline Mean (SD) Min - Max & & & & \\
\hline \multicolumn{5}{|l|}{ Gender } \\
\hline Female N (\%) & 23 & (57.50\%) & 37 & $(60.66 \%)$ \\
\hline \multicolumn{5}{|l|}{ Site } \\
\hline Leiden N (\%) & 10 & $(25 \%)$ & 17 & $(27.87 \%)$ \\
\hline London N (\%) & 10 & $(25 \%)$ & 16 & $(26.23 \%)$ \\
\hline Paris N (\%) & 10 & $(25 \%)$ & 13 & $(21.31 \%)$ \\
\hline Ulm N (\%) & 10 & $(25 \%)$ & 15 & $(24.59 \%)$ \\
\hline Total Motor Score & \multirow{2}{*}{$1.38(1.85)$} & \multirow{2}{*}{$0-7$} & \multirow{2}{*}{$\begin{array}{l}20.07 \\
(10.73)\end{array}$} & \multirow{2}{*}{$6-58$} \\
\hline Mean (SD) Min-Max & & & & \\
\hline Total Functional Capacity & \multirow{2}{*}{$12.98(0.16)$} & \multirow{2}{*}{$12-13$} & \multirow{2}{*}{$11.74(1.45)$} & \multirow{2}{*}{$5-13$} \\
\hline Mean (SD) Min-Max & & & & \\
\hline \multicolumn{3}{|l|}{ CAG } & \multirow{2}{*}{$43.77(3.20)$} & \multirow{2}{*}{$39-54$} \\
\hline \multicolumn{3}{|l|}{ Mean (SD) Min - Max } & & \\
\hline Disease Burden Score * & & & \multirow{2}{*}{$\begin{array}{l}376.46 \\
(85.15)\end{array}$} & \multirow{2}{*}{$\begin{array}{l}226.41 \\
559.18\end{array}$} \\
\hline Mean (SD) Min - Max & & & & \\
\hline $\begin{array}{l}\text { Total Functional Capacity } \\
\text { Breakdown by site }\end{array}$ & & & 3 & \\
\hline \multicolumn{5}{|l|}{$\mathrm{N}(\%)$} \\
\hline TFC 11-13 (HD Stage 1) & & 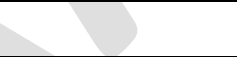 & 56 & $(91.80 \%)$ \\
\hline TFC 7-10 (HD Stage 2) & & 3 & $4^{a}$ & $(6.56 \%)$ \\
\hline TFC 3-6 (HD Stage 3) & & & $1^{b}$ & $(1.64 \%)$ \\
\hline
\end{tabular}

\section{Effect sizes}

ES for the difference in 6-, 9- and 15-month change between HD participants and controls are presented in Table 2. Unadjusted baseline, 6- and 15-month findings for each outcome, with the number of data points for each variable, are presented by group in Supplemental Tables 3 and 4, with adjusted between-group differences in change over the 6-, 9-, and 15-month intervals. 


\begin{tabular}{|c|c|c|c|}
\hline & \multicolumn{3}{|c|}{ Effect Size Estimate (95\% Cl) } \\
\hline & 6-month interval & 9-month interval & 15-month interval \\
\hline \multicolumn{4}{|l|}{ Cognitive battery } \\
\hline Letter Fluency & $\begin{array}{l}0.133 \\
(-0.4,0.603)\end{array}$ & $\begin{array}{l}0.618 \\
(-0.074,1.183)\end{array}$ & $\begin{array}{l}0.664 \\
(-0.031,1.32) \\
\end{array}$ \\
\hline Category Fluency & $\begin{array}{l}0.226 \\
(-0.212,0.663)\end{array}$ & $\begin{array}{l}0.125 \\
(-0.417,0.662)\end{array}$ & $\begin{array}{l}0.348 \\
(-0.204,0.892)\end{array}$ \\
\hline HVLT delayed recall & $\begin{array}{l}0.491 \\
(-0.006,0.926)\end{array}$ & $\begin{array}{l}0.001 \\
(-0.525,0.531)\end{array}$ & $\begin{array}{l}0.502 \\
(-0.122,1.033)\end{array}$ \\
\hline HVLT total correct & $\begin{array}{l}0.115 \\
(-0.357,0.589)\end{array}$ & $\begin{array}{l}0.119 \\
(-0.329,0.609)\end{array}$ & $\begin{array}{l}0.208 \\
(-0.181,0.584)\end{array}$ \\
\hline HVLT Recognition & $\begin{array}{l}0.189 \\
(-0.147,0.449) \\
\end{array}$ & $\begin{array}{l}-0.264 \\
(-0.692,0.075)\end{array}$ & $\begin{array}{l}-0.159 \\
(-0.837,0.32) \\
\end{array}$ \\
\hline Symbol Digit Modalities Test (SDMT) & $\begin{array}{l}0.637 \\
(0.08,1.154)\end{array}$ & $\begin{array}{l}0.343 \\
(-0.108,0.808)\end{array}$ & $\begin{array}{l}0.799 \\
(0.344,1.254)\end{array}$ \\
\hline Trail A Time (seconds) & $\begin{array}{l}0.209 \\
(-0.103,0.471)\end{array}$ & $\begin{array}{l}-0.055 \\
(-0.369,0.31)\end{array}$ & $\begin{array}{l}0.212 \\
(-0.115,0.574)\end{array}$ \\
\hline Trail B Time (seconds) & $\begin{array}{l}0.114 \\
(-0.265,0.443) \\
\end{array}$ & $\begin{array}{l}-0.23 \\
(-0.678,0.164) \\
\end{array}$ & $\begin{array}{l}-0.073 \\
(-0.492,0.25) \\
\end{array}$ \\
\hline Stroop Word & $\begin{array}{l}0.285 \\
(-0.086,0.573)\end{array}$ & $\begin{array}{l}0.063 \\
(-0.257,0.448)\end{array}$ & $\begin{array}{l}0.305 \\
(-0.081,0.614)\end{array}$ \\
\hline Stroop Colour & $\begin{array}{l}0.25 \\
(-0.191,0.684)\end{array}$ & $\begin{array}{l}0.192 \\
(-0.227,0.594)\end{array}$ & $\begin{array}{l}0.36 \\
(-0.026,0.705)\end{array}$ \\
\hline Stroop Interference & $\begin{array}{l}0.176 \\
(-0.194,0.539)\end{array}$ & $\begin{array}{l}0.303 \\
(-0.11,0.685)\end{array}$ & $\begin{array}{l}0.492 \\
(-0.026,0.943)\end{array}$ \\
\hline \multicolumn{4}{|l|}{ UHDRS clinical scales } \\
\hline TMS (square root) & $\begin{array}{l}0.047 \\
(-0.473,0.609)\end{array}$ & $\begin{array}{l}0.58 \\
(0.087,1.096)\end{array}$ & $\begin{array}{l}0.545 \\
(0.075,1.123)\end{array}$ \\
\hline TFC score & $\begin{array}{l}0.337 \\
(-0.532,1.325)\end{array}$ & $\begin{array}{l}0.176 \\
(-1.05,1.323)\end{array}$ & $\begin{array}{l}0.388 \\
(-0.478,1.241)\end{array}$ \\
\hline \multicolumn{4}{|c|}{ Microstructural (diffusion) neuroimaging metrics } \\
\hline Caudate FA & $\begin{array}{l}0.37 \\
(-0.125,0.826)\end{array}$ & $\begin{array}{l}0.285 \\
(-0.109,0.651)\end{array}$ & $\begin{array}{l}0.518 \\
(0.12,0.878)\end{array}$ \\
\hline Caudate $\mathrm{MD}\left(\mathrm{mm}^{2} / \mathrm{s}\right)$ & $\begin{array}{l}0.539 \\
(0.199,0.83) \\
\end{array}$ & $\begin{array}{l}0.62 \\
(0.173,1.029)\end{array}$ & $\begin{array}{l}1.111 \\
(0.77,1.434)\end{array}$ \\
\hline Caudate RD $\left(\mathrm{mm}^{2} / \mathrm{s}\right)$ & $\begin{array}{l}0.522 \\
(0.178,0.815)\end{array}$ & $\begin{array}{l}0.611 \\
(0.178,1.017)\end{array}$ & $\begin{array}{l}1.067 \\
(0.729,1.387)\end{array}$ \\
\hline Caudate AD $\left(\mathrm{mm}^{2} / \mathrm{s}\right)$ & $\begin{array}{l}0.562 \\
(0.211,0.859)\end{array}$ & $\begin{array}{l}0.627 \\
(0.145,1.059) \\
\end{array}$ & $\begin{array}{l}1.174 \\
(0.839,1.493)\end{array}$ \\
\hline Putamen FA & $\begin{array}{l}-0.036 \\
(-0.359,0.301)\end{array}$ & $\begin{array}{l}-0.206 \\
(-0.558,0.152)\end{array}$ & $\begin{array}{l}-0.269 \\
(-0.654,0.139)\end{array}$ \\
\hline Putamen MD $\left(\mathrm{mm}^{2} / \mathrm{s}\right)$ & $\begin{array}{l}0.433 \\
(0.147,0.72) \\
\end{array}$ & $\begin{array}{l}0.286 \\
(-0.074,0.636)\end{array}$ & $\begin{array}{l}0.723 \\
(0.384,1.017)\end{array}$ \\
\hline Putamen RD $\left(\mathrm{mm}^{2} / \mathrm{s}\right)$ & $\begin{array}{l}0.328 \\
(0.06,0.603)\end{array}$ & $\begin{array}{l}0.217 \\
(-0.154,0.562)\end{array}$ & $\begin{array}{l}0.567 \\
(0.231,0.868)\end{array}$ \\
\hline Putamen AD $\left(\mathrm{mm}^{2} / \mathrm{s}\right)$ & $\begin{array}{l}0.553 \\
(0.229,0.851)\end{array}$ & $\begin{array}{l}0.379 \\
(0.034,0.723)\end{array}$ & $\begin{array}{l}0.92 \\
(0.526,1.261)\end{array}$ \\
\hline White Matter FA & 0.234 & -0.089 & 0.165 \\
\hline
\end{tabular}


Hobbs et al. p11

\begin{tabular}{|c|c|c|c|}
\hline & $(-0.164,0.638)$ & $(-0.477,0.285)$ & $(-0.284,0.65)$ \\
\hline White Matter MD ( $\left.\mathrm{mm}^{2} / \mathrm{s}\right)$ & $\begin{array}{l}0.499 \\
(0.072,0.93)\end{array}$ & $\begin{array}{l}0.188 \\
(-0.148,0.536)\end{array}$ & $\begin{array}{l}0.615 \\
(0.197,1.095)\end{array}$ \\
\hline White Matter RD $\left(\mathrm{mm}^{2} / \mathrm{s}\right)$ & $\begin{array}{l}0.39 \\
(-0.053,0.785)\end{array}$ & $\begin{array}{l}0.103 \\
(-0.21,0.419)\end{array}$ & $\begin{array}{l}0.506 \\
(0.08,0.944)\end{array}$ \\
\hline White matter $A D\left(\mathrm{~mm}^{2} / \mathrm{s}\right)$ & $\begin{array}{l}0.495 \\
(0.075,0.887)\end{array}$ & $\begin{array}{l}0.275 \\
(-0.074,0.813)\end{array}$ & $\begin{array}{l}0.614 \\
(0.212,1.139)\end{array}$ \\
\hline Corpus Callosum FA & $\begin{array}{l}0.432 \\
(0.112,0.818)\end{array}$ & $\begin{array}{l}0.148 \\
(-0.206,0.471)\end{array}$ & $\begin{array}{l}0.681 \\
(0.17,1.147)\end{array}$ \\
\hline Corpus Callosum MD $\left(\mathrm{mm}^{2} / \mathrm{s}\right)$ & $\begin{array}{l}0.249 \\
(-0.183,0.763)\end{array}$ & $\begin{array}{l}0.147 \\
(-0.304,0.562)\end{array}$ & $\begin{array}{l}0.304 \\
(-0.117,0.899)\end{array}$ \\
\hline Corpus Callosum RD $\left(\mathrm{mm}^{2} / \mathrm{s}\right)$ & $\begin{array}{l}0.371 \\
(-0.004,0.876)\end{array}$ & $\begin{array}{l}0.102 \\
(-0.318,0.498)\end{array}$ & $\begin{array}{l}0.413 \\
(-0.048,1.034)\end{array}$ \\
\hline Corpus Callosum AD (mm $/ \mathrm{mm}^{2} \mathrm{~s}$ & $\begin{array}{l}0.015 \\
(-0.351,0.379)\end{array}$ & $\begin{array}{l}0.235 \\
(-0.235,0.641)\end{array}$ & $\begin{array}{l}0.211 \\
(-0.157,0.719)\end{array}$ \\
\hline \multicolumn{4}{|c|}{ Macrostructural (volumetric) neuroimaging metrics } \\
\hline Caudate atrophy, CBSI (\% baseline) & $\begin{array}{l}0.697 \\
(0.359,1.021) \\
\end{array}$ & $\begin{array}{l}0.638 \\
(0.324,0.981) \\
\end{array}$ & $\begin{array}{l}1.191 \\
(0.742,1.687)\end{array}$ \\
\hline Whole-brain atrophy, BBSI (\% baseline) & $\begin{array}{l}0.479 \\
(0.157,0.774)\end{array}$ & $\begin{array}{l}0.698 \\
(0.314,1.064)\end{array}$ & $\begin{array}{l}0.865 \\
(0.465,1.199)\end{array}$ \\
\hline Ventricular expansion, VBSI (mls) & $\begin{array}{l}0.791 \\
(0.412,1.143)\end{array}$ & $\begin{array}{l}0.925 \\
(0.553,1.279)\end{array}$ & $\begin{array}{l}1.025 \\
(0.672,1.323)\end{array}$ \\
\hline Grey matter atrophy (\% baseline) & $\begin{array}{l}0.772 \\
(0.243,1.23)\end{array}$ & $\begin{array}{l}0.612 \\
(0.304,1.101)\end{array}$ & $\begin{array}{l}0.86 \\
(0.554,1.219)\end{array}$ \\
\hline White matter atrophy (\% baseline) & $\begin{array}{l}0.615 \\
(0.261,1.028)\end{array}$ & $\begin{array}{l}0.93 \\
(0.566,1.283)\end{array}$ & $\begin{array}{l}0.957 \\
(0.589,1.325)\end{array}$ \\
\hline Putamen atrophy (\% baseline) & $\begin{array}{l}0.101 \\
(-0.187,0.397)\end{array}$ & $\begin{array}{l}0.538 \\
(0.2,0.899)\end{array}$ & $\begin{array}{l}0.777 \\
(0.331,1.183)\end{array}$ \\
\hline Corpus callosal atrophy (\% baseline) & $\begin{array}{l}0.113 \\
(-0.272,0.557)\end{array}$ & $\begin{array}{l}0.170 \\
(-0.213,0.609)\end{array}$ & $\begin{array}{l}0.205 \\
(-0.191,0.63)\end{array}$ \\
\hline \multicolumn{4}{|c|}{ Macrostructural (cortical thinning) neuroimaging metrics } \\
\hline Frontal lobe cortical thinning ( $\mathrm{mm})$ & $\begin{array}{l}-0.097 \\
(-0.519,0.292)\end{array}$ & $\begin{array}{l}-0.054 \\
(-0.513,0.42)\end{array}$ & $\begin{array}{l}-0.173 \\
(-0.76,0.406)\end{array}$ \\
\hline Parietal lobe cortical thinning $(\mathrm{mm})$ & $\begin{array}{l}0.043 \\
(-0.315,0.415)\end{array}$ & $\begin{array}{l}0.247 \\
(-0.153,0.647)\end{array}$ & $\begin{array}{l}0.376 \\
(-0.109,0.855)\end{array}$ \\
\hline Temporal lobe cortical thinning (mm) & $\begin{array}{l}0.293 \\
(-0.154,0.752)\end{array}$ & $\begin{array}{l}0.058 \\
(-0.326,0.51)\end{array}$ & $\begin{array}{l}0.254 \\
(-0.122,0.695)\end{array}$ \\
\hline Occipital lobe cortical thinning (mm) & $\begin{array}{l}0.295 \\
(-0.161,0.771)\end{array}$ & $\begin{array}{l}0.22 \\
(-0.196,0.667)\end{array}$ & $\begin{array}{l}0.512 \\
(0.011,0.997)\end{array}$ \\
\hline
\end{tabular}

Table 2. 6-, 9- and 15-month Effect Size Estimates.

ES estimates and 95\% bias corrected and accelerated Cls over 6-, 9- and 15-month intervals for differences between change in HD and control participants.All analyses adjusted for age, gender and study site as well as interactions with the linear and quadratic effects of time. Models for non-imaging outcomes adjusted additionally for educational level and its interactions with linear and quadratic effects of time. Expression of results as ES permits comparison of changes measured using different metrics. Such ES (when squared) are inversely related to sample-size requirements for clinical trials under the assumption that a $100 \%$ effective treatment will reduce the mean rate of change in HD to that in healthy controls, without affecting the variability. 
For clinical applicability, Table 2 should be viewed in conjunction with Figure 1, which depicts the relationship between ES and sample-size requirements for diseasemodifying clinical trials (where the outcome is a single change measured between two time points) for varying assumed treatment efficacies.

\section{Macrostructural neuroimaging measures}

Longitudinal atrophy of the caudate, white-matter, grey-matter and whole-brain, and expansion of the lateral ventricles, produced relatively large ES over 6-, 9- and 15-month intervals (Table 2); with all between-group differences statistically significant $(p<0.05$, Supplemental Table 4). ES for these metrics were relatively consistent in that they tended to change in magnitude relative to the interval size. Caudate atrophy and ventricular expansion performed particularly strongly over the 6-month interval.

Putamen atrophy ES were small and not statistically significant over the 6-month interval (ES 0.101; 95\% Cl $-0.187,0.397$ ) but performed more strongly over 9- and 15months, although ES were smaller than for the caudate and the other more global atrophy metrics listed above (Table 2). Corpus callosal atrophy was not significantly higher than in controls over all time intervals examined (Supplemental Table 3).

Cortical thinning ES were small and between-group differences were only statistically significant for the occipital cortex over the 15-month interval $(p=0.032$, Supplemental Table 3); however this ES was relatively small with a wide $\mathrm{Cl}(0.512 ; 95 \% \mathrm{Cl} 0.011$, 0.997).

\section{Microstructural neuroimaging measures}

The microstructural (diffusion) metrics had typically smaller ES than the macrostructural atrophy measurements, although the caudate diffusivity metrics performed strongly (Table 2, Supplemental Table 3). In particular, caudate MD produced ES comparable to caudate atrophy over the 9- and 15-month intervals.

FA ES were small and not statistically significant progression over all intervals and for all structures examined (caudate, putamen, global white-matter and corpus callosum).

\section{Clinical measures}

The standard clinical scales examined (TFC and TMS) performed relatively poorly. Between-group differences in TFC were not statistically significant over 6-, 9- or 15month intervals (Supplemental Table 3) and corresponding ES were small, with Cls spanning zero. TMS performed more strongly than TFC over the 9- and 15-month intervals, with significant between-group differences and larger ES, although the Cls 
surrounding the ES estimates were wide (TMS over 15 months; ES 0.545 ( $95 \% \mathrm{Cl}$ : 0.075, 1.123)).

\section{Cognitive measures}

Changes in the majority of tasks in the cognitive battery did not differ significantly between HD and controls over all intervals examined (Table 2, Supplemental Table 3). The Symbol Digit Modality Task (SDMT) was the most promising non-imaging measure over 15 months (ES 0.799; 95\% Cl: 0.344 to 1.254). However, this measure lacked consistency over the shorter intervals, with 6-month and 9-month ES of $0.637(95 \% \mathrm{Cl}$ : 0.08 to 1.154$)$ and $0.348(95 \% \mathrm{Cl}:-0.108,0.808)$ respectively. 


\section{DISCUSSION}

Employing a multi-site study design with variable, short-interval observational periods, we report 6-, 9- and 15-month ES for a range of biomarker candidates of HD progression across multiple assessment modalities (macro- and micro-structural neuroimaging, clinical and cognitive). Reported ES can be used with a standard formula to calculate sample-size requirements for disease-modifying clinical trials ${ }^{10}$ (Figure 1 ). This is the first time that ES have been reported over the short intervals of six and nine months. It is hoped that these data will be used to directly inform clinical trial design.

\section{Key Results}

Longitudinal changes in macrostructural neuroimaging measures such as caudate atrophy and ventricular expansion in early HD subjects were larger than those in controls giving rise to consistently large ES over the 6-, 9- and 15-month intervals, in agreement with previous multi-site observational findings over periods of 12-months and longer (Tabrizi 2011, 2012, 2013 etc). Analogous ES for cortical metrics were smaller particularly over the shorter intervals, although occipital cortical thinning showed some promise over 15 months. Microstructural (diffusion) neuroimaging metrics ES were also typically smaller over the shorter intervals, although caudate diffusivity metrics performed strongly over 9 and 15 months, in line with the most promising atrophy measures. To our knowledge, this is the first longitudinal multi-site study to examine change in diffusion metrics in HD. Findings are encouraging, particularly within the striatal grey matter, in accordance with a recent report over 18 months in a single-site study (Dominguez PLOS one 2013).

Clinical and cognitive outcomes exhibited small longitudinal ESs, particularly over 6- and 9-month intervals, with wide confidence intervals indicating a lack of precision. Of note, SDMT appeared particularly promising over the 6-month interval, producing ES comparable with caudate atrophy, although with noticeably wider confidence intervals. However, this result was not replicated over the 9-month interval, suggesting it to be a chance finding. Over 15 months, SDMT performed strongly, producing ES comparable with putamen atrophy. These longer-interval findings are in line with previous reports over 12- and 24-months, showing SDMT to be one of the most promising cognitive outcomes (Tabrizi 2011, 2012. Paulsen. Stout JNNP 2012).

\section{Interpretation: Clinical application}

To interpret findings within the context of designing disease-modifying clinical trials in $\mathrm{HD}$, we must consider that although certain neuroimaging measures appear to be particularly powerful, they would not be accepted as primary end-points in trials since they do not provide a direct measure of how the patient feels, functions or survives (www.fda.gov). Hence, to exploit the potential of these neuroimaging measures, we propose their use as: (1) initial short-term readouts in early phase/proof-of-concept (PoC) studies over six months; (2) interim or safety readouts over six or nine months in 
longer, larger efficacy studies (e.g. Phase III), and as; (3) secondary end-points in efficacy studies over longer periods such as 15 months.

\section{Short-term readouts}

Macrostructural neuroimaging measures such as caudate atrophy and ventricular expansion may be able provide early confidence-instilling readouts in Phase II PoC studies over intervals such as 6 and 9 months months, where the goal would be to assure safety and gather initial evidence that the therapy had promising properties. Encouraging findings from such readouts would facilitate the decision whether to further invest in the therapy, increasing participant numbers and trial duration. An adaptive approach such as this based on early, meaningful data could improve the viability of disease-modifying clinical trials in HD.

\section{Interim read-outs and secondary end-points}

Once sufficiently powered, disease-modification could be demonstrated in large-scale Phase III efficacy studies of longer duration such as 15 months, using approved clinical measures such as TMS as the primary end-point, and specific neuroimaging metrics as secondary end-points. Supportive data from a strong neuroimaging biomarker programme would be important in demonstrating disease modification. 
Objective: to assess the effects of the therapy on the progression of:

\begin{tabular}{|c|c|c|c|c|c|c|c|c|}
\hline & $\begin{array}{l}\text { Global } \\
\text { atrophy }\end{array}$ & $\begin{array}{l}\text { Subcortical } \\
\text { GM } \\
\text { atrophy }\end{array}$ & $\begin{array}{l}\text { WM } \\
\text { atrophy }\end{array}$ & $\begin{array}{l}\text { Cortical } \\
\text { atrophy }\end{array}$ & \begin{tabular}{c|} 
GM \\
microstructural \\
degeneration
\end{tabular} & $\begin{array}{c}\text { WM } \\
\text { microstructural } \\
\text { degeneration }\end{array}$ & $\begin{array}{l}\text { Cognitive } \\
\text { decline }\end{array}$ & $\begin{array}{l}\text { Motor } \\
\text { signs }\end{array}$ \\
\hline \multicolumn{9}{|l|}{ Biomarker candidate } \\
\hline & $\begin{array}{l}\text { Ventricular } \\
\text { expansion }\end{array}$ & $\begin{array}{l}\text { Caudate } \\
\text { atrophy }\end{array}$ & $\begin{array}{l}\text { WM } \\
\text { atrophy }\end{array}$ & $\begin{array}{l}\text { Occipital } \\
\text { contical } \\
\text { thinning }\end{array}$ & $\begin{array}{c}\text { Caudate } \\
\text { MD }\end{array}$ & WM & SDMT & $\begin{array}{l}\text { UHDRS } \\
\text { TMS }\end{array}$ \\
\hline \multicolumn{9}{|l|}{$\begin{array}{l}\text { Sample-size requirements: } \\
50 \% \text { treatment effect }\end{array}$} \\
\hline 6-month interval & $\begin{array}{c}134 \\
(64,495)\end{array}$ & $\begin{array}{c}173 \\
(81,652)\end{array}$ & $(80,12234)$ & $\begin{array}{c}966 \\
(141, \text { inf })\end{array}$ & $\begin{array}{c}289 \\
(122,2123)\end{array}$ & $\begin{array}{c}338 \\
(97,16215)\end{array}$ & $\begin{array}{c}207 \\
(63,13134)\end{array}$ & $\begin{array}{c}38053 \\
(227, \text { inf })\end{array}$ \\
\hline 9-month interval & $\begin{array}{c}98 \\
(51,275)\end{array}$ & $\begin{array}{c}207 \\
(87,801)\end{array}$ & $\begin{array}{c}97 \\
(51,262)\end{array}$ & $\begin{array}{c}1737 \\
(189, \text { inf })\end{array}$ & $\begin{array}{c}219 \\
(79,2809)\end{array}$ & $\begin{array}{c}2378 \\
(293,3838)\end{array}$ & $\begin{array}{l}714 \text { (129, inf) } \\
\text { (12) }\end{array}$ & $\begin{array}{l}250 \\
(70,11106)\end{array}$ \\
\hline 15-month interval & $\begin{array}{c}80 \\
(48,186)\end{array}$ & $\begin{array}{l}59 \\
(30,153)\end{array}$ & $\begin{array}{c}92 \\
(48,242)\end{array}$ & $\begin{array}{c}321 \\
(85,694706)\end{array}$ & $\begin{array}{c}68 \\
(41,142)\end{array}$ & $\begin{array}{c}222 \\
(70,2166)\end{array}$ & $\begin{array}{c}132 \\
(53,710)\end{array}$ & $\begin{array}{c}283 \\
(67,14944)\end{array}$ \\
\hline $\begin{array}{l}\text { Guidelines for usage in future } \\
\text { disease modifying studies }\end{array}$ & $\downarrow$ & $\downarrow$ & $\downarrow$ & $\downarrow$ & $\downarrow$ & $\downarrow$ & $\downarrow$ & $\downarrow$ \\
\hline $\begin{array}{l}\text { Proof-of-concept studies } \\
\text { - short terms readouts } \\
\text { over } 6 \text { months }\end{array}$ & $\checkmark$ & $\sqrt{ }$ & ? & $\mathbf{x}$ & $?$ & ? & $x$ & $x$ \\
\hline $\begin{array}{l}\text { Large scale efficacy studies } \\
\text { - interim readouts } \\
\text { over } 9 \text { months }\end{array}$ & $\checkmark$ & $\sqrt{ }$ & $\checkmark$ & $\mathbf{x}$ & ? & ? & $\mathbf{x}$ & $?$ \\
\hline $\begin{array}{l}\text { - longer term readouts } \\
\text { over } 15 \text { months }\end{array}$ & $\checkmark$ & $\checkmark$ & $\checkmark$ & $x$ & $\checkmark$ & $?$ & $\checkmark$ & $?$ \\
\hline
\end{tabular}

Figure $\mathbf{2}$ Suggested biomarker selection for trials of a $\mathbf{5 0 \%}$ effective disease-modifying agent Sample-size requirements are per treatment arm; calculated using the standard formula ${ }^{10}$, with $90 \%$ power and two-tailed $p<0.05$, for therapies with $50 \%$ estimated treatment efficacy. Recommendations are given as ticks ("show potential"), crosses ("unlikely to be suitable") and question marks ("further data required - wide confidence intervals").

Figure 2 provides an example of how the ES data presented in Table 2 could be used to inform clinical trial design. Sample-size requirements are presented for the most promising outcomes from each assessment modality (Table 2), based on a treatment hypothesised to reduce the rate of change in each outcome by $50 \%$ (90\% power and $5 \%$ significance level). Based on these results, recommendations for selecting biomarkers for short PoC studies and longer-term Phase III trials are provided as "ticks" (show potential), "crosses" (unlikely to be suitable) and "question marks" (further data is required due to wide confidence intervals). An important caveat of this figure is that sample sizes are heavily dependent on the magnitude of the hypothesised treatment effect (Figure 1). For example, requirements would be $4 x$ larger if the effect was reduced to $25 \%$. Nevertheless, this approach does provide an estimate of sample-size requirements to sufficiently power trials, as well as a means of comparing the outcomes across assessment modalities.

For example, in order to detect therapeutic effects on ventricular expansion following treatment periods of 6-, 9- or 15-months, sample-size requirements per treatment arm would be 134 (95\% Cl: 64, 495), 98 (95\% Cl: 51, 275) and 80 (95\% Cl: 48, 186) respectively, for $50 \%$ efficacy. Considering the magnitude of the sample sizes and the 
width of the confidence intervals, ventricular expansion may be a suitable biomarker for use in short-term PoC studies, as well as trials over a longer duration (Figure 2).

Conversely, to assess the effect of a therapy on motor progression, the commonlyapplied UHDRS-TMS may be suitable for use over 9- and 15-month intervals, given a $50 \%$ treatment effect; however, the wide confidence intervals around these sample sizes indicate a lack of precision (Figure 2).

\section{Generalizability}

It is important to note that observational data should only be used to inform clinical trials involving similar cohorts and observational periods. The current study focussed on stage $1 \mathrm{HD}$, the very early clinical phase of the disease, since disease-modifying treatments are most likely to be efficacious in preserving function and quality of life when administered at this point. Therapies shown to be effective in these cohorts within an acceptable safety profile, may be administered during the premanifest stages of the disease, prior to clinical onset. The observational PREDICT-HD study, which focuses on the premanifest stages of the disease, is ideally positioned to inform the design of such trials (Paulsen).

\section{Limitations}

We must acknowledge the potential limitations of using neuroimaging biomarkers as efficacy readouts. It is possible that a positive macrostructural neuroimaging readout over six or nine months may not be indicative of longer-term clinical or functional improvement. Although associations between change in neuroimaging measures and functional decline have been reported in HD, causality is yet to be demonstrated. ${ }^{6}$ Furthermore, these readouts may not be suitable for all types of intervention; their utility may be dependent on the mechanism-of-action of the therapy, together with the time required for it to mediate an effect. Nevertheless, these neuroimaging measures are show, on average, greater changes in HD cases than controls even over short timeframes, reproducible across sites and objective. They may provide valuable biomarkers in the assessment of disease-modifying compounds.

None of the participants in the current study were enrolled in clinical trials; however, many were on medications which target the central nervous system (CNS) (Supplemental Table 2). However, mean dosages of CNS-targeting drugs were relatively low, with overlap in usage between groups. This study was not designed to examine the specific effects of medication on each outcome; however, we acknowledge medication usage as a potential confounder.

\section{Conclusion}

The short-interval observational data presented here are complimentary to findings over longer intervals in others such as the TRACK-HD and the PREDICT-HD studies. 
Taken together, these studies can provide data to directly inform the design of clinical trials in $\mathrm{HD}$, facilitating the evaluation of treatments designed to slow the course of this devastating disease. Since HD is often regarded as a model neurodegenerative disease, amenable to early intervention, ${ }^{1}$ research into this disorder may inform earlyintervention strategies for more prevalent neurodegenerative diseases. 


\section{ACKNOWLEDGEMENT}

The authors would like to thank the patients and controls who took part in this study, along with all the PADDINGTON study Work Package 2 site staff at Paris, Leiden, UIm and London, and Eileanoir Johnson for her assistance with the medication table. Funding/support: This work has been supported by the European Union - PADDINGTON project, contract no. HEALTH-F2-2010-261358. RIS is supported by the CHDI/High Q Foundation, a not for profit organization dedicated to finding treatments for Huntington's disease. This work was undertaken at UCLH/UCL which received a proportion of funding from the Department of Health's NIHR Biomedical Research Centres funding scheme. SJT acknowledges support of the National Institute for Health Research through the Dementias and Neurodegenerative Research Network, DeNDRoN. Role of the sponsor: The funding organisation were not involved in the design and conduct of the study; collection, management, analysis, or interpretation of the data; preparation, review, or approval of the manuscript; or decision to submit the manuscript for publication. Information on author access to data: SJT had full access to all the data in the study and takes responsibility for the integrity of the data and the accuracy of the data analysis. Disclosure of potential conflicts of interest: None

\section{PADDINGTON Work-Package 2 contributors:}

1. Research Project: A. Organisation, B. Execution, C. Administration 2. Collaborators in PADDINGTON consortium

Netherlands: Dr Ellen 't Hart MSc, Verena Rödig MSc, Anne Schoonderbeek MSc (Leiden University of Medical Sciences). UK: Victoria Perry BSc (1C), Nicola Robertson BSc (1B) (UCL Institute of Neurology, London). France: Dr Perrine Charles MD PhD, Dr Claire Ewenczyk MD, Dr Stephan Klebe MD (Assistance Publique-Hôpitaux de Paris, Paris), Dr Damien Justo PhD (Université Pierre et Marie Curie, Paris). Germany: Sabrina Betz Dipl., Dr Jens Dreyhaupt PhD, Carolin Eschenbach, Ms Jeton Iseni, Daniela Schwenk, Dr Michael Orth Associate Professor MD, Sonja Trautmann, Nurse, Ms Karin Schiefele, Diploma, Irina Blankin BSc, Ms Theresia Kelm BSc, Rosine Scherer Dipl., Felix Mudoh Tita MSc, Katja Vitkin (UIm University). Italy: Dr Giovanna Tripepi PhD (2), Dr Giuseppe Pollio PhD (2) (Siena Biotech SpA). 


\section{FIGURES}

TABLES

Reference List

1 Ross,C.A. and Tabrizi,S.J. (2011) Huntington's disease: from molecular pathogenesis to clinical treatment. Lancet Neurol. 10, 83-98

2 Berger,J.R. et al. (2013) Importance and Hurdles to Drug Discovery for Neurological Disease. Annals of Neurology 74, 441-446

3 Dominguez,J.F. et al. (2013) Multi-Modal Neuroimaging in Premanifest and Early Huntington's Disease: 18 Month Longitudinal Data from the IMAGE-HD Study. Plos One 8

4 Tabrizi,S.J. et al. (2012) Potential endpoints for clinical trials in premanifest and early Huntington's disease in the TRACK-HD study: analysis of 24 month observational data. Lancet Neurol.

5 Tabrizi,S.J. et al. (2011) Biological and clinical changes in premanifest and early stage Huntington's disease in the TRACK-HD study: the 12-month longitudinal analysis. Lancet Neurol. 10, 31-42

6 Tabrizi,S.J. et al. (2009) Biological and clinical manifestations of Huntington's disease in the longitudinal TRACK-HD study: cross-sectional analysis of baseline data. Lancet Neurol. 8, 791-801

7 Tabrizi,S.J. et al. (2013) Predictors of phenotypic progression and disease onset in premanifest and early-stage Huntington's disease in the TRACK-HD study: analysis of 36month observational data. Lancet Neurology 12, 637-649

8 Paulsen,J.S. et al. (2006) Preparing for preventive clinical trials: the Predict-HD study. Arch. Neurol. 63, 883-890

9 Aylward,E.H. et al. (2011) Longitudinal change in regional brain volumes in prodromal Huntington disease. J. Neurol. Neurosurg. Psychiatry 82, 405-410

10 Julious,S.A. (2009) Sample sizes in clinical trials, Boca Raton: Chapman and Hall

11 Hobbs,N.Z. et al. (2013) Evaluation of multi-modal, multi-site neuroimaging measures in Huntington's disease: Baseline results from the PADDINGTON study. Neuroimage: Clinical 2, 204-211 
12 Kieburtz,K. et al. (1996) Unified Huntington's disease rating scale: Reliability and consistency. Movement Disorders 11, 136-142

13 Muller,H.P. et al. (2013) Evaluating multicenter DTI data in Huntington's disease on site specific effects: An ex post facto approach. Neuroimage Clin. 2, 161-167

14 Freeborough,P.A. et al. (1997) Interactive algorithms for the segmentation and quantitation of 3-D MRI brain scans. Computer Methods and Programs in Biomedicine $53,15-25$

15 Freeborough,P.A. and Fox,N.C. (1997) The boundary shift integral: an accurate and robust measure of cerebral volume changes from registered repeat MRI. IEEE Trans. Med. Imaging 16, 623-629

16 Leung,K.K. et al. (2010) Robust atrophy rate measurement in Alzheimer's disease using multi-site serial MRI: tissue-specific intensity normalization and parameter selection. Neuroimage. 50, 516-523

17 Magnotta,V.A. et al. (2002) Structural MR image processing using the BRAINS2 toolbox. Comput. Med. Imaging Graph. 26, 251-264

18 Hobbs, N.Z. et al. (2010) The progression of regional atrophy in premanifest and early Huntington's disease: a longitudinal voxel-based morphometry study. J Neurol. Neurosurg. Psychiatry 81, 756-763

19 Christensen,G.E. et al. (1996) Deformable templates using large deformation kinematics. leee Transactions on Image Processing 5, 1435-1447

20 Reuter,M. et al. (2012) Within-subject template estimation for unbiased longitudinal image analysis. Neuroimage 61, 1402-1418

21 Desikan,R.S. et al. (2006) An automated labeling system for subdividing the human cerebral cortex on MRI scans into gyral based regions of interest. Neuroimage 31, 968980

22 Carpenter,J. and Bithell,J. (2000) Bootstrap confidence intervals: when, which, what? A practical guide for medical statisticians. Stat. Med. 19, 1141-1164

23 Rothman,K.J. (1990) No adjustments are needed for Multiple Comparisons. Epidemiology 1, 43-46

24 Penney,J.B. et al. (1997) CAG repeat number governs the development rate of pathology in Huntington's disease. Annals of Neurology 41, 689-692

25 Rosas,D. et al. (2014) PRECREST: A phase II prevention and biomarker trial of creatine in at-risk Huntington's Disease. Neurology 82, 1-8 
Hobbs et al. p22

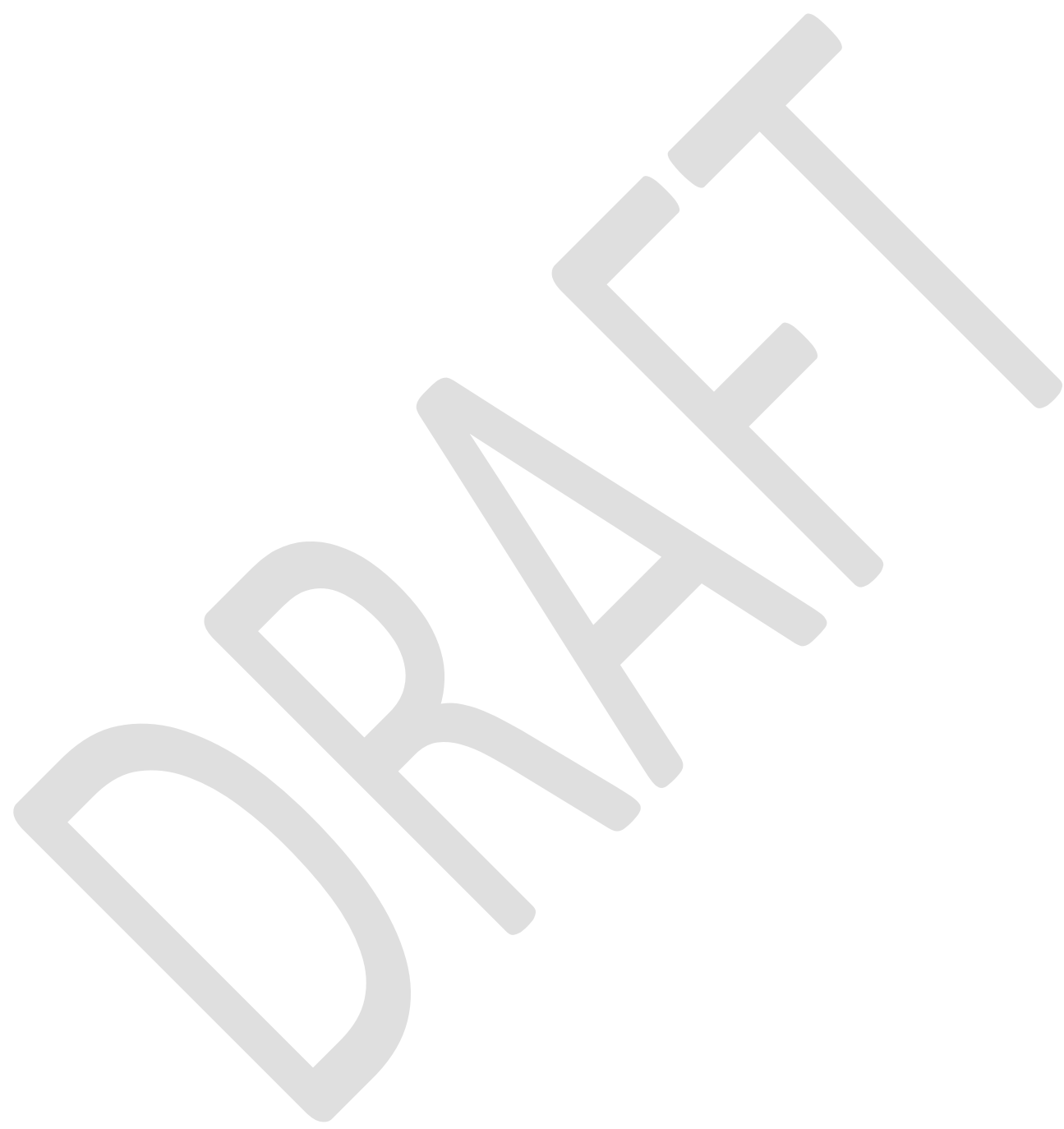

